(RESEARCH ARTICLE)

\title{
Evaluation of serum irisin, retinol-binding protein-4 in human obesity
}

\author{
Qussay Noori Raddam*
}

Education College, University of AL-Iraqia, Iraq-Baghdad.

GSC Biological and Pharmaceutical Sciences, 2021, 15(01), 081-086

Publication history: Received on 04 March 2021; revised on 12 April 2021; accepted on 14 April 2021

Article DOI: https://doi.org/10.30574/gscbps.2021.15.1.0100

\begin{abstract}
Retinol-binding protein 4(RBP4), and irisin originally described as an adipocyte-specific hormone, has been suggested to be an important link between obesity, insulin resistance and diabetes. To test the hypothesis that irisin and RBP4, and insulin concentrations will be higher in obese subject than in normal weight. A total of 176 individuals were evaluated, which divided into three groups according to BMI. Group I (Normal Weight group n=75), Group II (Over Weight group, $n=50$ ), Group III (Obese group, $n=51$ ). Serum irisin RBP4and insulin levels were evaluated by enzymelinked immunosorbent assay. The statistical analysis (students t-test) exhibited significant (P>0.0001)elevation for Serum RBP4 , Irisin, and insulin in over weight and obese groups compared with normal weight groups $\{(57.6 \pm 16.0)$, and $(70.1 \pm 19.9) v s(41.8 \pm 13.3) \mu \mathrm{g} / \mathrm{ml} ; \mathrm{p}<0.001\},\{(168.19 \pm 11.71)$ and $(171.35 \pm 11.81) \mathrm{vs}(146.19 \pm 9.13) \mathrm{ng} / \mathrm{mL}$ : $\mathrm{p}<0.05\},\{(7.25 \pm 2.04)$, and $(9.02 \pm 4.75)$ vs $(4.91 \pm 1.87) \mathrm{mU} / \mathrm{mL} ; \mathrm{p}<0.001\}$ respectively. Linear regression analysis showed significant positive correlations between serum insulin with RBP4 and, Irisin.
\end{abstract}

Conclusion: In the cross sectional study, obese individuals had significant upregulation of circulating irisin, and RBP4 compared to non-obese subjects.

Keywords: Irisin; Insulin sensitivity; Retinol-binding protein 4; Obesity

\section{Introduction}

Obesity is generally defined by a body mass index of $>30 \mathrm{~kg} / \mathrm{m} 2$ with overweight beginning at $>25 \mathrm{~kg} / \mathrm{m}^{2}$. Overweight is caused by a chronic imbalance of energy intake and energy expenditure. Environmental, social, and economical changes have massively changed dietary and physical activity patterns (1).

Adipose tissue secretes various adipokines that play important roles in the modulation of a variety of biological functions. Retinol binding protein 4 (RBP4), belongs to the lipocalin family of proteins, is the major transport protein which secreted by adipocytes and liver and initially known as the specific carrier of retinol (vitamin A) in circulation (2).

Irisin is a newly discovered plasma myokine/adipokine that is results from C-terminal cleavage of the fibronectin type III domain-containing (FNDC) 5 transmembrane protein, which is the product of the FNDC5 gene which induced by the peroxisome proliferator-activated receptor- coactivator-1 that causes brown coloration of white fat, promotes fat burning and inhibits weight gain (3).

Therefore, the objective of this study was to evaluate the serum concentration of irisin and RBP4, and insulin in obese, overweight and normal weight adult patients, correlating the concentrations of this biomarker with IR rates in the study population.

\footnotetext{
${ }^{*}$ Corresponding author: Qussay Noori Raddam

Education College / University of AL-Iraqia /Iraq-Baghdad.
} 


\section{Material and methods}

In the current study 176 individuals were selected from Tikrit Teaching Hospital in Tikrit city between February 2016 and April 2017. There were divided into three groups as following:

G I: Normal Weight: 75 volunteers were recruited in this group, which had a BMI ranging from 18.5 - 24.9.

G II: - Over Weight group: 50volunteers were recruited in this group. Their BMIs ranging from 25.0 - 29.9.

GIII: - Obese group: 51 volunteers were recruited in this group, Their BMIs were $\geq 30$.

BMI was calculated as weight in kilograms divided by the square of height in meters. BMI= weight $(\mathrm{kg}) / \mathrm{height}$ (m)2(4)..Waist circumference (WC) was measured in centimeters $(\mathrm{cm})$ at the end of normal expiration half way between the lowest rib and the iliac crest with the investigator standing at the side to ensure that the measuring tape is horizontal across the back and the front of the participant(5).

Blood samples were obtained from all participants after a 12-h overnight fast and immediately centrifuged. Serum samples were stored at $-8{ }^{\circ} \mathrm{C}$ until measurements of irisin, RBP 4 and insulin levels were determined using sandwich ELISA.

Data were evaluated with SPSS software for Windows (version 11.0; SPSS Inc., Chicago, IL). Data were presented as mean SD. Differences between groups were evaluated with a Mann-Whitney test. Pearson correlation and logistic regression analysis were carried out to determine the relationship between the variables. All tests were two-tailed, and the significance level was defined as P .05.

\section{Results}

Table 1 Basic characteristics of study population.

\begin{tabular}{|l|l|l|l|}
\hline Weight groups & Age (years) & BMI $(\mathrm{Kg} / \mathbf{m} 2)$ & WC (CM). \\
\hline Normal weight & $29.375 \pm 4.683$ & $20.266 \pm 1.78$ & $75.13 \pm 5.84$ \\
\hline Overweight & $38.789 \pm 3.876$ & $27.11 \pm 1.567$ & $93.36 \pm 4.1$ \\
\hline Obese & $44.548 \pm 4.741$ & $33.462 \pm 3.212$ & $101.53 \pm 8.6$ \\
\hline P & 0.0001 & 0.0001 & 0.0001 \\
\hline
\end{tabular}

Table 1 shows the demographic and anthropometric characteristics of each group. BMI $\left(\mathrm{Kg} / \mathrm{m}^{2}\right)$ was significantly higher for the obese group (33.462 \pm 3.212$)$, than the overweight $(27.11 \pm 1.567)$, and normal weight $(20.266 \pm 1.78)$.

The mean \pm SD of WC in the different weight groups was (101.53 \pm 8.6$),(93.36 \pm 4.1)$, and $(75.13 \pm 5.84)$ Cm, respectively.

Table 2 Mean distribution of biochemical parameters in study group.

\begin{tabular}{|l|l|l|l|l|}
\hline & normal weight & Overweight & Obese Mean \pm SD & P value \\
\hline Serum RBP4 $(\mu \mathrm{g} / \mathrm{ml})$ & $41.8 \pm 13.3$ & $57.6 \pm 16.0^{*}$ & $70.1 \pm 19.9^{*}, \dagger$ & $<0.001$ \\
\hline Irisin $(\mathrm{ng} / \mathrm{mL})$ & $146.19 \pm 9.13$ & $168.19 \pm 11.71$ & $171.35 \pm 11.81$ & $p<0.05$ \\
\hline Fasting insulin $(\mathrm{mU} / \mathrm{mL}) \mathrm{a}$ & $4.91 \pm 1.87$ & $7.25 \pm 2.04^{*}$ & $9.02 \pm 4.75$ & $0.001^{*}$ \\
\hline
\end{tabular}

Table 1 shows demographic and biochemical characteristics of studied population. The irisin plasma levels for all groups are shown in Figure 2. The irisin serum levels $(\mathrm{ng} / \mathrm{mL})$ were significantly higher for the overweight and obese group $(168.19 \pm 11.71),(171.35 \pm 11.81)$ than for the normal weight $(146.19 \pm 9.13)$.

Mean levels of RBP4 were significantly higher $(\mathrm{P}<0.01)$, in overweight $(57.6 \pm 16.0 \mu \mathrm{g} / \mathrm{ml})$, and obese group $(70.1 \pm$ $19.9 \mu \mathrm{g} / \mathrm{ml}$ ) when compared with controls (41.8 \pm 13.3$)$ [P > 0.05, Figure 1]. 
For insulin, there was a significant increase in overweight and obese group (7.25 \pm 2.04$),(9.02 \pm 4.75)$ than for the normal weight (4.91 \pm 1.87$)$.

The results presented that there was positive correlation between insulin, with Irisin in over weight group ( $\mathrm{r}=0.167$ ), in obese group ( $r=0.165)$ also RBP4in over weight group $(r=0.105)$, in obese group $(r=0.115)$

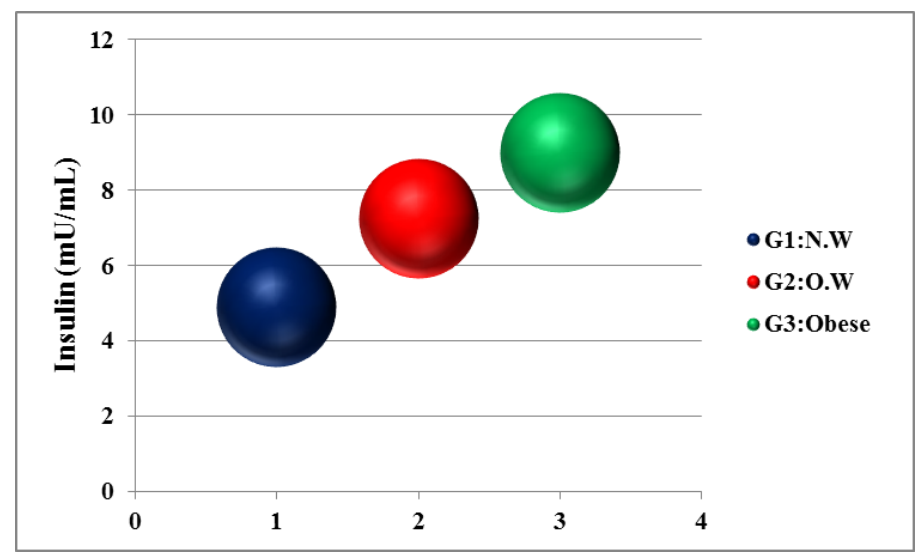

Figure 1 Insulin concentration in groups of study.

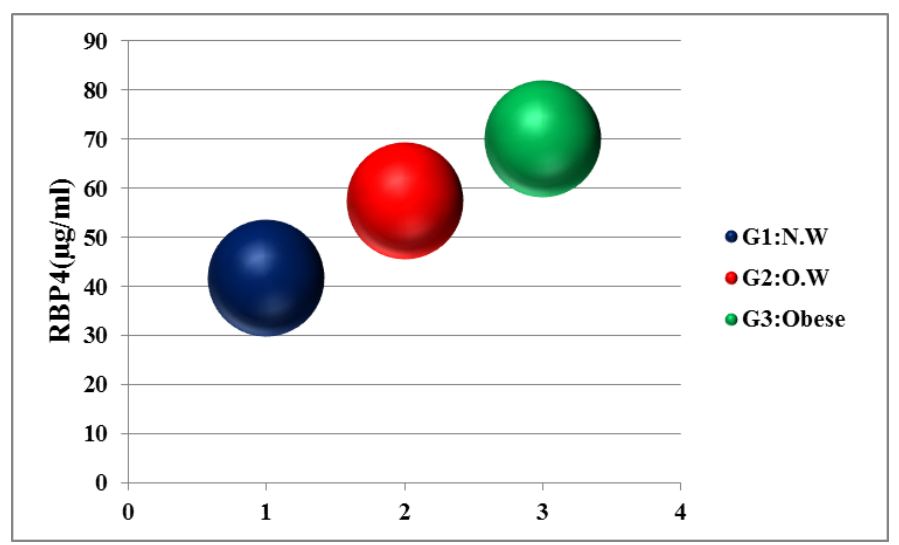

Figure 2 RBP4 concentration in groups of study.

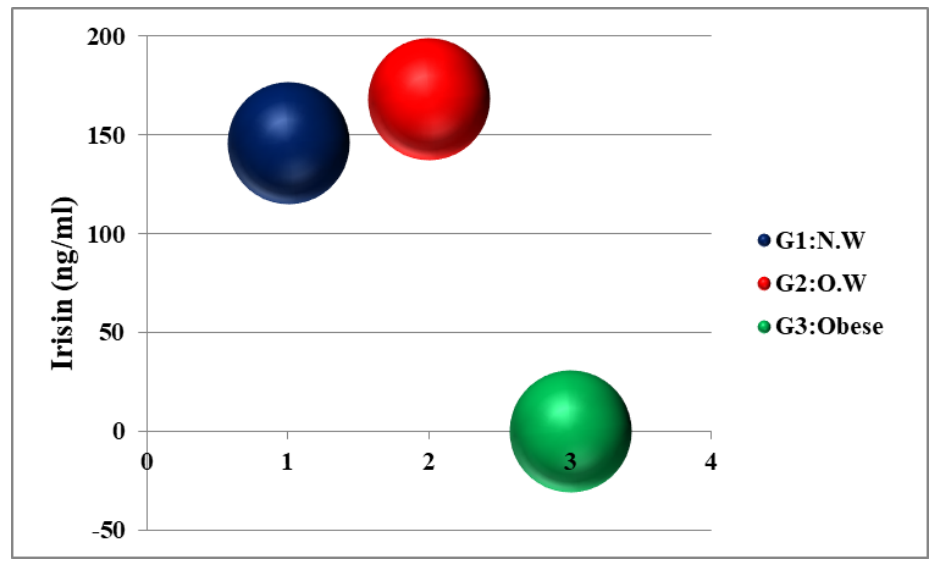

Figure 3 Irisin concentration in groups of study. 


\section{Discussion}

The results of our study showed that although RBP4 protein serum levels were higher in obese group in comparison to controls, the differences were significant. This finding was consistent with several other studies (6-9).

The strong relationship between adipose RBP4 protein and adiposity as reflected by BMI suggests that adipose tissue RBP4 expression may play a role in adipogenesis. Retinaldehyde, which is an oxidized derivative of retinol is expressed in adipose tissue and has been shown to inhibit adipogenesis, possibly through suppression of nuclear receptor responses (10). Although Kelly et al. (11)speculative that, there is the possibility increased RBP4 in adipose tissue binds and holds retinol, thus reducing retinaldehyde formation and the inhibition of adipogenesis in the cell, as well as strong association between adipose RBP4 expression and fasting glucose for the T2DM subjects, suggesting that upregulation of tissue RBP4 may be secondary to hyperglycemia. Retinol binding protein 4 has been proposed as a signal transferring protein involved in the regulation of systemic glucose metabolism and pathogenesis of insulin resistance.

In normal individuals, binding of insulin to its receptor on the cell membrane stimulates glucose uptake into muscle and fat cells through the GLUT4 transporter. It also inhibits glucose production in liver, thereby maintaining normal glucose levels in the blood. In adipose tissue, glucose provides fuel for the synthesis of fat stores, which serve as the body's main energy reservoir (12). High levels of RBP4 contribute to increase IR by modification of the GLUT4 transporter, inhibition of insulin signaling at muscle tissue level, and increasing liver glucose release, as well as by inhibition of insulin receptors substrate 1 (IRS1) in adipose tissue.

Suppression of GLUT4 might be independent of adipose RBP4 expression and might be due to other factors such as macrophage migration into adipose tissue, or overproduction of macrophage-derived cytokines, which result in reduced GLUT4 protein (13-15).

Janke et al. (16) found a down-regulation of RBP4 mRNA in subcutaneous fat in obese women, whereas Tan et al. (17)found an up-regulation of RBP4 mRNA expression in subcutaneous as well as in visceral fat depots in obese insulinresistant women with polycystic ovary syndrome.

Reduction in body weight after dietary interventions, especially with a carbohydrate-restricted diet, results in decreased serum RBP4 levels (18).

Irisin secretion might be explained by not only the total amount of fat mass or body muscle mass but also by the relative proportion of body muscle mass to fat mass. Accordingly, the Serum irisin level was higher in obese group than in overweight group, higher irisin levels in obese subjects reflect either an increased baseline secretion of irisin by the increased adipose and muscle tissue in obesity and/or a compensatory increase of irisin levels to combat obesity whereas the lowest irisin levels in the underweight group A possible explanation for the low irisin level in the underweight group is that irisin promotes the "browning" of subcutaneous white adipose tissue, capable of burning energy through uncoupling protein 1-mediated thermogenesis, and increased energy expenditure. Uncoupling protein 1 is an enzyme that uncouples oxidative phosphorylation from ATP production, leading to energy release as heat. The underweight group in this study had a lower fat mass and \% fat mass (19).

Furthermore, it was proposed that obesity may be associated with reduced irisin sensitivity and/or irisin resistance Thus, similar to the elevated levels of insulin and leptin in insulin and leptin resistance associated with human obesity, irisin levels are also elevated and similar to insulin or leptin, may play a compensatory role with respect to regulating energy expenditure and glucose metabolism in an attempt to restore glucose tolerance in obese subjects $(20,21)$.

Obesity-induced inflammation in pancreatic tissue promotes apoptosis of $\beta$-cells and results in insulin deficiency (22), irisin may play a vital role in pancreatic $\beta$-cell function (23). Irisin could contribute to the modulation of obesity-induced inflammatory/anti-inflammatory balance by increasing CD206 and interleukin 10 and decreasing tumor necrosis factor alpha and leptin (24). Furthermore, Irisin is related more strongly to insulin resistance than other myokines, which promotes the expression of $\beta$-trophin, another newly identified hormone that promotes pancreatic $\beta$-cell proliferation and improves glucose tolerance (25). Therefore, irisin was speculated to promote insulin secretion by increasing the proliferation or reducing the apoptosis of b-cells. Irisin is also related to metabolic parameters and may be useful for obesity treatment $(26,27)$, based on a proposed hypothesis for the anti-obesity effect of irisin (28). However, a consensus regarding irisin secretion has not been reached (29).

Further studies are needed to clarify the molecular mechanisms underlying the correlation of irisin with $\beta$-cell function and its role in insulin secretion in NGT (23). 


\section{Conclusion}

The results presented here assume that the determination of irisin, and RBP4 in the blood can be an important indicator of IR in obese individuals, and that in the future, the determination of serum levels of RBP4 may become simple, fast and efficient to predict metabolic risk factors related to IR, besides the cardiovascular risk factors, guiding the diagnosis, treatment and monitoring of this population.

To our knowledge this is the first study to investigate the possible predictive role of irisin in obesity. It needs to be further elucidated whether irisin plays any causative vs compensatory role in metabolic disorders.

\section{Compliance with ethical standards}

\section{Acknowledgments}

Our Acknowledgments for medicine college AL-Iraqi a University and Medicine college of Tikrit University.

\section{Disclosure of conflict of interest}

The authors declare that the research was conducted in the absence of any commercial or financial relationships that could be construed as a potential conflict of interest.

\section{Statement of informed consent}

All consents are obtained from the subjects of the study prior to the commencement of the screening process.

\section{References}

[1] Entedhar R. Sarhat. Study the levels of Leptin, and Adiponectin with Paraoxonase in Obese Individuals (male \& female). $2015 ; 20(2): 49-52$.

[2] Wongsiriroj N, Jiang H, Piantedosi R, Yang KJ, Kluwe J, Schwabe RF, et al. Genetic dissection of retinoid esterification and accumulation in the liver and adipose tissue. J Lipid Res. 2014; 55(1): 104-14.

[3] Andrew G. Swick. Irisin, a novel myokine: potential role in obesity and diabetes. Heart Metab. 2013 ; 61: 39-40.

[4] Suman S Dambal, Suchetha Kumari N. Evaluation of lipid peroxidation and total antioxidant status in human obesity; International Journal of Institutional Pharmacy and Life Sciences. 2012; 2(3): 2249-6807.

[5] WHO. Steps Manual. Part 3 Training and Practical Guides. Geneva: WHO 2008.

[6] Klöting N, Graham TE, Berndt J, et al. Serum retinol-binding protein is more highly expressed in visceral than in subcutaneous adipose tissue and is a marker of intra-abdominal fat mass. Cell Metab. 2007; 6: 79-87.

[7] Aeberli I, Biebinger R, Lehmann R, L'Allemand D, Spinas GA, Zimmermann MB. Serum retinol-binding protein 4 concentration and its ratio to serum retinol are associated with obesity and metabolic syndrome components in children. J Clin Endocrinol Metab. 2007; 92(11): 4359-65.

[8] Kowalska I, Straczkowski M, Adamska A, Nikolajuk A, Karczewska-Kupczewska M, Otziomek E, et al. Serum retinol binding protein 4 is related to insulin resistance and nonoxidative glucose metabolism in lean and obese women with normal glucose tolerance. J Clin Endocrinol Metab. 2008; 93(7): 2786-9.

[9] Santoro N, Perrone L, Cirillo G, Brienza C, Grandone A, Cresta N, et al. Variations of retinol binding protein 4 levels are not associated with changes in insulin resistance during puberty. J Endocrinol Invest. 2009; 32(5): 411-4.

[10] Ziouzenkova O, Orasanu G, Sharlach M, et al. Retinaldehyde represses adipogenesis and diet- Kelly KR, Kashyap SR, O'Leary VB, Major J, Schauer PR, Kirwan JP. Retinol-binding Protein 4 (RBP4) Protein Expression Is Increased in Omental Adipose Tissue of Severely Obese Patients. Obesity (Silver Spring, Md). 2010; 18(4): 663-666.

[11] Kelly KR, Kashyap SR, O’Leary VB, Major J, Schauer PR, Kirwan JP. Retinol-binding Protein 4 (RBP4) Protein Expression Is Increased in Omental Adipose Tissue of Severely Obese Patients. Obesity (Silver Spring, Md.). 2010; 18(4): 663-666.

[12] Chang L, Chiang S-H, Saltiel AR. Insulin Signaling and the Regulation of Glucose Transport. Molecular Medicine. 2004; 10(7-12): 65-71. 
[13] Ribel-Madsen R, Friedrichsen M, Vaag A, Poulsen P. Retinol-binding protein 4 in twins: regulatory mechanisms and impact of circulating and tissue expression levels on insulin secretion and action. Diabetes. 2009; 58: 54-60.

[14] Weisberg SP, McCann D, Desai M, et al. Obesity is associated with macrophage accumulation in adipose tissue. J Clin Invest. 2003; 112: 1796-1808.

[15] Yuan M, Konstantopoulos N, Lee J, et al. Reversal of obesity- and diet-induced insulin resistance with salicylates or targeted disruption of Ikк $\beta$. Science. 2001; 293:1 673-1677.

[16] Janke J, Engeli S, Boschmann M, Adams F, Bohnke J, Luft FC, Sharma AM, Jordan J. Retinolbinding protein 4 in human obesity. Diabetes. 2006; 55: 2805-2810.

[17] Tan BK, Chen J, Lehnert H, Kennedy R, Randeva HS. Raised serum, adipocyte and adipose tissue retinolbinding protein 4 in overweight women with polycystic ovary syndrome: effects of gonadal and adrenal steroids. J ClinEndocrinolMetab. 2007; 92: 2764-2772.

[18] Volek JS, Phinney SD, Forsythe CE, Quann EE, Wood RJ, et al. Carbohydrate restriction has a more favorable impact on the metabolic syndrome than a low fat diet. Lipids. 2009; 44: 297-309.

[19] Leticia Elizondo-Montemayor, Christian Silva-Platas, Alejandro Torres-Quintanilla, et al. Association of Irisin Plasma Levels with Anthropometric Parameters in Children with Underweight, Normal Weight, Overweight, and Obesity, BioMed Research International. 2017; Article ID 2628968, 11.

[20] Polonsky KS. Dynamics of insulin secretion in obesity and diabetes. Int. J. Obes. Relat. Metab. Disord. 2000; 24: S29-S33.

[21] Montez JM, Soukas A, Asilmaz E, Fayzikhodjaeva G, Fantuzzi G, et al. Acute leptin deficiency, leptin resistance, and the physiologic response to leptin withdrawal. Proc. Natl. Acad. Sci. USA. 2005; 102: 2537-2542.

[22] Donath MY, Shoelson SE. Type 2 diabetes as an inflammatory disease. Nat. Rev. Immunol. 2011; 11: 98-107.

[23] Yang M, Chen P, Jin H, Xie X, Gao T, et al. Circulating levels of irisin in middle-aged first-degree relatives of type 2 diabetes mellitus- correlation with pancreatic b-cell function. Diabetol. Metab. Syndr. 2014; 6: 133.

[24] Moreno-Navarrete JM, Ortega F, Serrano M, Guerra E, Pardo G, et al. Irisin is expressed and produced by human muscle and adipose tissue in association with obesity and insulin resistance. J. Clin. Endocrinol. Metab. 2013; 98: E769-E778.

[25] Zhang Y, Li R, Meng Y, Li S, Donelan W, et al. Irisin stimulates browning of white adipocytes through mitogenactivated protein kinase p38 MAP kinase and ERK MAP kinase signaling. Diabetes. 2014; 63: 514-525.

[26] Kurdiova T, Balaz M, Ukropcova B. Effects of obesity, diabetes and exercise on FNDC5 gene expression and irisin release in human skeletal muscle and adipose tissue: in vivo and in vitro studies. J Physiol. 2014; 592: 1091-1107.

[27] Bostrom P, Wu J, Jedrychowski MP, et al. A PGC1-alphadependent myokine that drives brown-fat-like development of white fat and thermogenesis. Nature. 2012; 481: 463-468.

[28] Huh JY, Panagiotou G, Mougios V, et al. FNDC5 and irisin in humans: I. Predictors of circulating concentrations in serum and plasma and II. mRNA expression and circulating concentrations in response to weight loss and exercise. Metabolism. 2014; 1725-1738.

[29] Elsen M, Raschke S, Eckel J. Browning of white fat: does Irisin play a role in humans? J Endocrinol. 2014; 222: 2538. 